\title{
EVALUATION OF THE PROPERTIES OF POLYPROPYLENE / BANANA FIBRE BIOCOMPOSITES.
}

\author{
C. T. P. CONINCK ${ }^{1}$, L. G. S. BITENCOURT ${ }^{1}$, D. E.O.S. CARPENTER ${ }^{1}$ and I.O.B. \\ BARCELLOS 1
}

\author{
${ }^{1}$ University of Blumenau - Post-Graduation Program in Chemistry - FURB \\ Contact e-mail: deysec@yahoo.com
}

\begin{abstract}
A new bio-composite was developed by adding banana tree fibres to a polypropylene matrix. Banana fibre was chosen due to its abundance and relative low coat. The physical, chemical, mechanical and thermal properties of the bio-composite were investigated. The material was characterized using the following tests; Izod impact resistance, tensile strength, hardness, specific weight and differential scanning Calorometry (DSC). The banana fibres (BF) were extracted from pseudosterm of banana tree and mixed with a thermoplastic polypropylene (PP) compound in the proportions of 90/10\% (PP/BF), 80/20\% $(\mathrm{PP} / \mathrm{BF})$ e $70 / 30 \%$ (PP/BF) by weight, using an extrusion process to prepare the samples. The properties were compared with PP (100\%). The composites made of PP matrix containing banana fibre showed an improvement in impact properties as well as specific weight and thermal conductivity. Chemical and thermal stability also improved.
\end{abstract}

\section{INTRODUCTION}

Polypropylene (PP) is a very important semi crystalline thermoplastic for technological applications due to its strength, excellent melt processability, fast crystallization, low density, good mechanical properties and high thermal stability. Polypropylene has a long-term durability against environmental degradation and may experience some biodegradability if mixed with natural fibres (Xiaofei et al., 2008; Howard, 2002). The difficulty of synthetic polymer materials to degrade led to the development of sugar biopolymers. (Howard, 2002). However the mechanical properties of biopolymers are inferior to synthetic polymers for the majority of the commercial applications. Composites are very singular materials as they distribute the properties of all components. The most used materials for reinforcement of polymer composites by the plastic industry are natural fibres and minerals (Park et al., 2008). In the last decade a huge emphasis has been made on the fabrication and use of polymer natural fibre composites instead of synthetic fibres such as glass fibre, carbon fibre, Kevlar amongst others mainly because of costs and the environmental impact these materials cause (Barcellos et al., 2009; Martinelli, 2008).

Biodiversity allows an enormous amount of natural vegetable fibre options that could be used in polymer composites. Furthermore vegetable fibres are renewable resources with a high potential to modify thermoplastic. The most common are; sisal, jute, curaua, coconut, sugar cane bagasse, wood powder and banana tree fibre. Kaemple et al. (2002) observed that PP natural fibre composites require special preparation of the fibres prior impregnation into the matrix. 
The aim of this work was to develop a new composite with some degree of biodegradability and good mechanical properties. To reach the objective banana fibre pseudo stem was selected due to its high abundance and low cost.

\section{EXPERIMENTAL}

\subsection{Fibre Preparation}

The fibre used was from the banana plant pseudostem supplied by Cooperativa Musa Brazil. The extraction of the natural fibre from the plant requires care so as to avoid fibre damage. Sections were cut from the banana plant main stem which were subsequently lightly rolled to remove excess moisture. Excess impurities in the form of pigments, broken fibres and cellulose coating were removed by means of a manual comb. The fibres were then cleaned with hypochlorite, dried, milled and sieved. The fibres were then cut with a pair of scissors to the size of $10 \mathrm{~cm}$, grounded by electric mill Retsch ZM 1000 to the range of 200120 mesh, finally the samples were placed in to an oven at $110^{\circ} \mathrm{C}$ during $60 \mathrm{~min}$ and transferred to a desiccator.

\subsection{PP/FB Composites Preparation}

The polymer used was polypropylene (PP) and was provided by Sasil Com. Ind. Petroquímica LTDA. The composite material preparation was carried out by dispersing the fibre $(\mathrm{BF})$ previously prepared in to the PP matrix at $160{ }^{\circ} \mathrm{C}$, under agitation during $15 \mathrm{~min}$ usingmanual extruder. PP/BF were blended at different wt/wt ratio as follow; 100/0, 90/10, $80 / 20$ and $70 / 30$. After extrusion the material was transferred to moulds to obtain 7 specimens for each composition for each test according to the ASTM D 638-77 (American Society for Testing and Materials) for tensile strength and ASTM D256-78 (American Society for Testing and Materials) for impact test. For the other experiments the specimens were cut to the size of $128 \times 100 \times 3 \mathrm{~mm}$ from plates of the composite, following methodology from the literature (Selke, 2007).

\section{RESULTS AND DISCUSSION}

DSC curves of PP homopolymer and the polymer composites 90/10 (PP/BF), 80/20 (PP/BF) and 70/30 (PP/BF) are shown in Figure 1 and the values of relevant thermodynamic parameters are summarized in Figure 1. The PP sample and composites samples, 90/10 (PP/BF), 80/20 (PP/BF), $70 / 30(\mathrm{PP} / \mathrm{BF})$ shown one endothermic peak at $143,9^{\circ} \mathrm{C} ; 148,4{ }^{\circ} \mathrm{C} ; 147,4{ }^{\circ} \mathrm{C}$ and 144,8 ${ }^{\circ} \mathrm{C}$, respectively. The thermal stability was on the range of -85 to $400{ }^{\circ} \mathrm{C}$. The thermal stability is related to the absence of degradation pick in the thermograms. It was not detected characteristic discontinuity on the Tg value. 


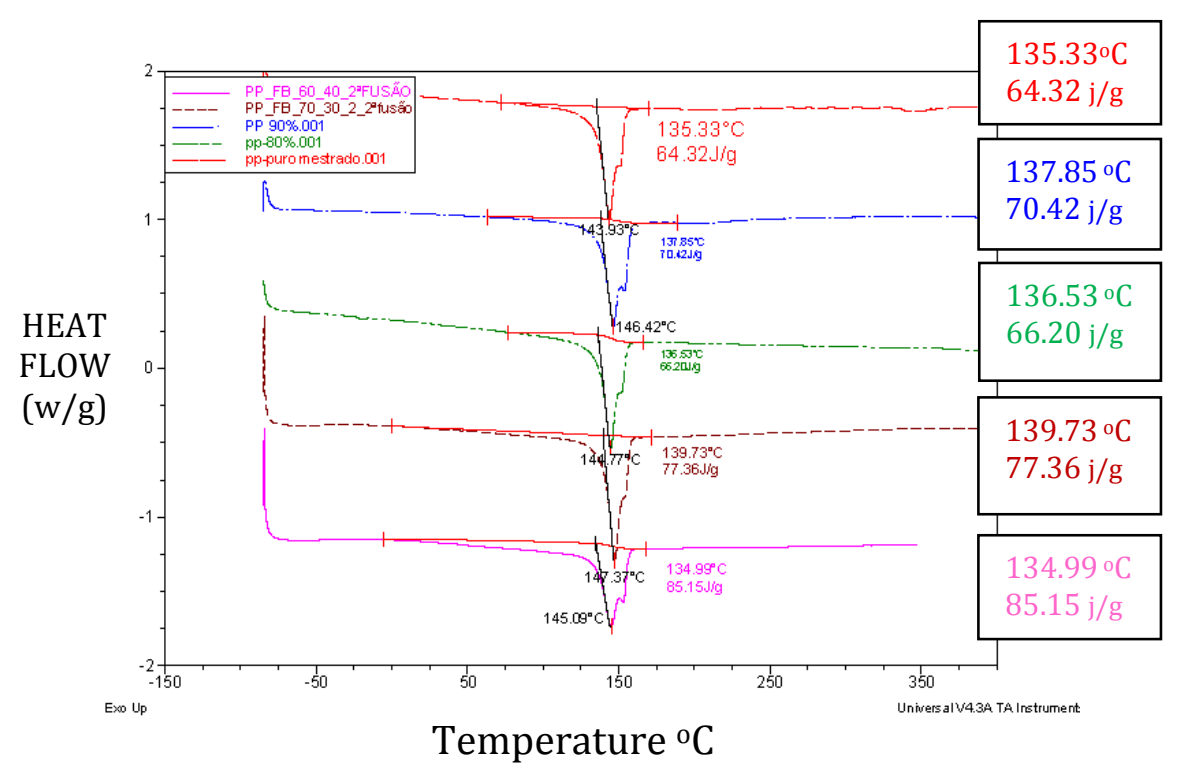

Figure 1 - DSC termograms of PP, 90/10\% (PP/BF), 80/20\% (PP/BF) and 70/30\% (PP/BF).

The melting temperatures (Tm) shown in table 1 do not change by much with the banana fibre addition. The small change in $\Delta \mathrm{H}$ values may indicate poor interaction between fibre and the PP matrix. Joseph et al. (2003) reported the thermal properties of sisal, polypropylene and their composite. The lignin present in the sisal fibre was degraded in temperatures in the range of 60 to $200{ }^{\circ} \mathrm{C}$ and the cellulose decomposed at $350{ }^{\circ} \mathrm{C}$. The PP pure decomposed at superior temperature in relation to the sisal fibre. The composite showed higher thermal stability than that of the sisal fibre or pure PP. In this study the results were different probably because sisal is richer in cellulose fibre than the pseudo stem of banana plant.

Table 1 - Thermal analysis of banana pseudsterm fibre and PP composites (PP/FB)

\begin{tabular}{|l|l|l|}
\hline $\begin{array}{l}\text { PP/FB } \\
(\%)\end{array}$ & $\begin{array}{l}\text { Melting Point } \\
\left({ }^{\circ} \mathrm{C}\right)\end{array}$ & $\begin{array}{l}\text { Enthalpy change }(\Delta \\
\mathrm{H}) \mathrm{J} / \mathrm{g}\end{array}$ \\
\hline $100 / 0$ & 135.3 & 64.32 \\
\hline $90 / 10$ & 137.8 & 70.42 \\
\hline $80 / 20$ & 136.5 & 66.20 \\
\hline $70 / 30$ & 139.7 & 77.33 \\
\hline
\end{tabular}

PP decomposed at $398^{\circ} \mathrm{C}$, which was higher than the fibre. An interesting finding was the fact that the composites degraded later than the PP pure, indicating that the thermal stability of the composite is higher than pure PP. This increased stability of composite 
compared to literature results for sisal fibre may be due to the latter presents improved fibrematrix interaction as suggested by George et al. (1996). The DTG curves obtained in the study further confirmed the superior thermal stability of such composites. In sisal/PP composite two peaks were obtained: a minor peak at $368{ }^{\circ} \mathrm{C}$ which corresponds to the degradation of cellulose and a major peak at $476{ }^{\circ} \mathrm{C}$ which corresponds to the degradation of cellulose. The initial peak was higher than the individual values of sisal which have the starting peak at $65{ }^{\circ} \mathrm{C}$ followed by another at $350{ }^{\circ} \mathrm{C}$. The composite peak had a slightly lower value of individual starting peak of PP at $400{ }^{\circ} \mathrm{C}$, but majority of the degradation for the composite was at $476{ }^{\circ} \mathrm{C}$ which was a significant improvement over the constituents. Thus the thermal stability was improved for PP-sisal composite. This indicates that the flammability of the PP-sisal composite would be less than the PP pure.

The figures 2 and 3 show the chemical stability of the samples. The composite $70 / 30$ (PP/BF) presented higher values of mass loss and consequently has lower chemical stability, approximately $10 \%$. For all the other samples the mass loss was smaller than $2 \%$ in all medium used, except by the $80 / 20$ (PP/BF) composite in acidic solution that presented mass loss of $3.8 \%$.

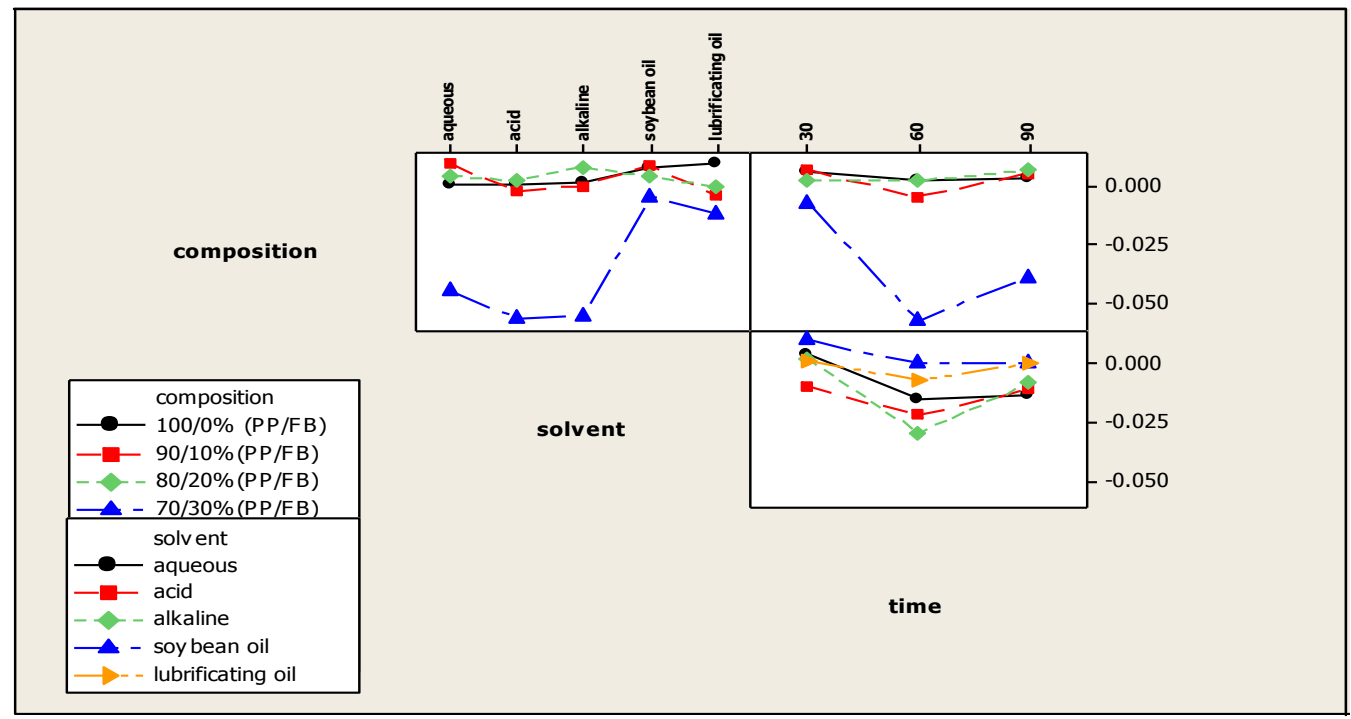

Figure 2 - The main effects of mass loss of the samples studied.

The mass loss values for the samples 100/0, 90/10 e 80/20 (PP/BF) were very close together. The only sample that showed considerable mass loss was 70/30 (PP/BF) in aqueous, acidic and alkaline medium during 60 days and presented low mass loss in edible and lubricating oils during 30 and 80 days of immersion. The fact that the chemical stability. Was good in oils shows important characteristics for application in packaging.

The results of the toughness test for pure PP and all composition of banana fibre are presented in the table 2. It is observed that the addition of banana fibre up to $20 \%$ in to the PP matrix increases the toughness of the material in relation to the value of pure PP. When the composition of the fibre riches $30 \%$ it was noticed that the toughness decreased. This 
behaviour may be explained due to difficulty of homogeneously distribute the banana fibre in to the polymer compromising the toughness test result (Shibata, et al, 2005). The interface between the fibre and the polymer matrix is very important in the mechanical properties of the composite. The interface physical bond on the molecular arrangement and the chemical proprieties of the fibre and matrix (Ichazo et al., 2001). Murkhopadhyay et al. (2008) studied the influence of sisal fibre on the toughness resistance of the composite for both sisal as received or sisal chemically treated the resistance results were very similar with the as received fibre being slightly higher. The increase of toughness resistance is related to the plasticizing effect at the interface banana fibre/ PP matrix (Rohlmann et al., 2008; Rahmann et al., 2008). However it is found in the literature similar results to this work it is also related opposite behaviour, but it is understood that the toughness resistance is very sensitive to the type of fibre and matrix (Rohlmann et al., 2008; Rahmann et al., 2008; Liu et al., 2009).

Table 2 - Toughness resistance of the pure PP and fibre and PP composites (PP/FB)

\begin{tabular}{|l|l|}
\hline PP/BF composition $(\%)$ & Toughness resistance $(\mathrm{J} / \mathrm{m})$ \\
\hline $100 / 0$ & 6.7 \\
\hline $90 / 10$ & 15.5 \\
\hline $80 / 20$ & 20.0 \\
\hline $70 / 30$ & 6.7 \\
\hline
\end{tabular}

Figure $4 \mathrm{a}$ presents the results of the tensile strength for the pure PP and for the banana fibre composites $90 / 10,80 / 20,70 / 30$. It is not observed significant difference in tensile results for the composition up to $20 \%$ of banana tree fibre that is very similar to the pure PP. On the other hand the 70/30 PP/BF composite showed tensile strength about $54 \%$ smaller than pure PP. This behaviour shows that there is no influence of the banana tree fibre as received on the mechanical propriety of the polymer composite. However, the literature reports opposite behaviour for other fibres such as sisal, roselle, henequem and linen and also it is related to hydration because when the fibre is dehydrated the tensile strength increased (Rohlmann et al., 2008; Park et al., 2008; Pracella et al., 2006; Franco and González., 2003)
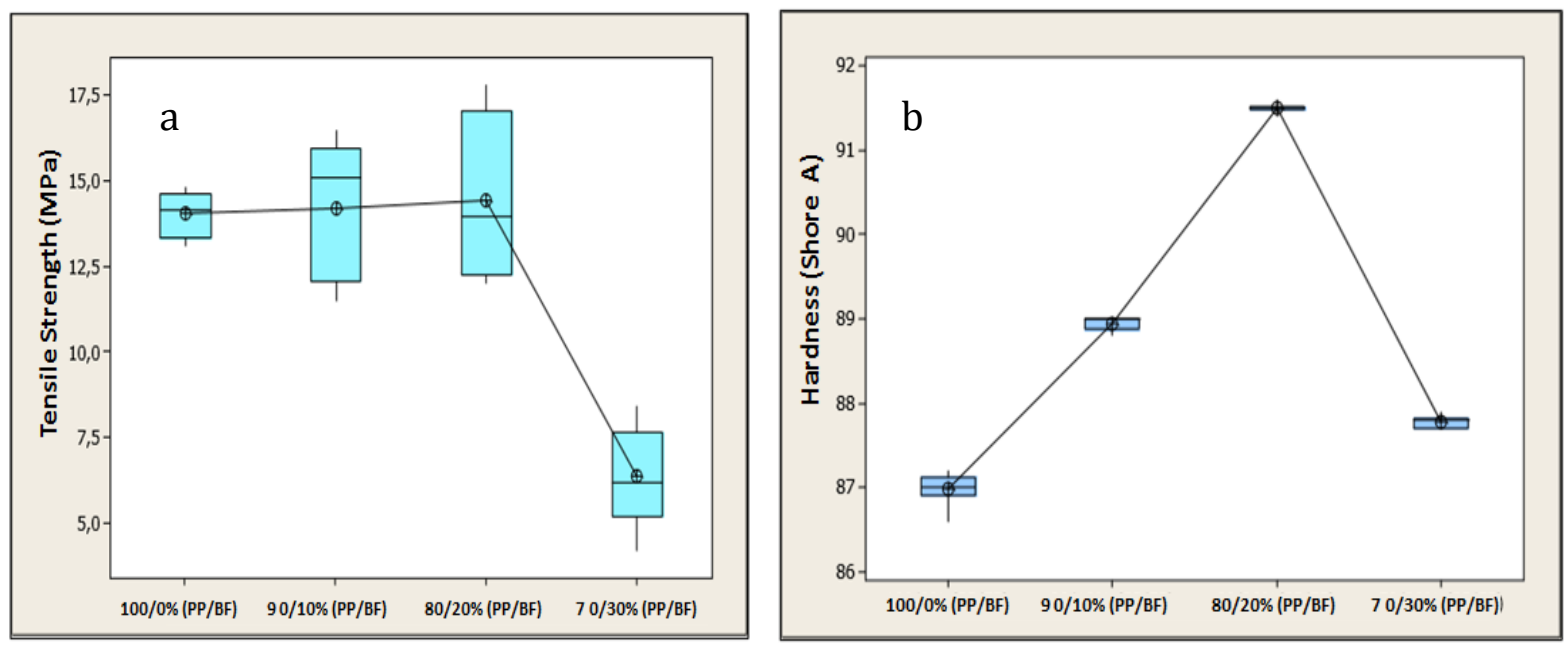

Figure 4 - a)Tensile Strength values for pure PP and 90/10, 80/20, 70/30 banana fibre/ PP composite. b) Hardness values for pure PP and 90/10, 80/20, 70/30 banana fibre/ PP composite. 
The hardness measurements are presented in the figure $4 \mathrm{~b}$. A very discrete increase on the hardness of the $90 / 10$ and $80 / 20$ composite in relation to the pure PP was observed. However the values of the 70/30 composite $h$ very hardness are the same as for pure PP. This behaviour shows there is very little influence of the banana tree fibre in the hardness of the material.

\section{CONCLUSIONS}

This study showed the banana tree fibre composite with fibre addition of $30 \%$ is not homogeneous decreasing the mechanical proprieties of the composite prepared.

Thermal stability slightly increased was observed for the composites studied in relation to the pure PP indicating good processability of the material. The enthalpy increased by $10 \%$ for the 90/10 and 80/20 PP/BF composites but for the 70/30 composite the enthalpy increase was around $20 \%$ indicating poor interaction between fibre and PP matrix.

In the range of the fibre concentration used in this study was observed changes on the density of the composites. The specific weight increased with concentration of the fibre in relation to the pure PP. The composites with 90/10 and 80/20 PP/BF composition presented good chemical stability in all the medium used in this study, however, it was observed that higher concentrations of banana tree fibre decreases considerably the chemical stability in the studied mediums except in oils.

The mechanical proprieties were influenced by the composition of the composites. It was observed increase of toughness for the samples with 90/10 and 80/20 PP/BF composite. The hardness increased for the 90/10 and 80/20 PP/TB composite in relation to the pure PP. There was a important reduction in tensile strength for the sample 70/30 PP/BF and for the other two compositions the tensile strength was kept without alteration in relation to the pure PP.

\section{REFERENCES}

ALVES, V.; COSTA, N.; HILLIOU, L.; LAROTONDA, F.; GONÇALVES, M.; SERENO, A.; COELHOSO, I. Design of biodegradable composite films for food packaging Desalination. v. 199, p. 331 - 333, 2006.

AMERICAN SOCIETY FOR TESTING AND MATERIALS. ASTM D256: Standard Test Method for Determining the Izod Pendulum Impact Resistance of Plastics.

AMERICAN SOCIETY FOR TESTING AND MATERIALS. ASTM D638-77: Standard Test Method for Tensile Propreties of Plastics.

AMERICAN SOCIETY FOR TESTING AND MATERIALS. ASTM D792: Standard Test Method for Density and Specific Gravity (Relative Density) of Plastics by Displacement. 
BARCELLOS, I.O. ; SOUZA, A. C.; SELKE, A. E. Incorporação de Lodo Industrial em compósitos de Resina de Poliéster. Polímeros: Ciência e Tecnologia. v. 19, n. 2, p. 155 - 159 , 2009.

BORGER, A.; HEISE, B.; TROLL, C.; MARTI, O.; RIEGER, B. Mechanical and Temperature Dependant Properties Structure and Phase Transitions of Elastic Polypropylene. Europen Polymer Journal, v. 43, p. 634-643, 2007.

BUSICO, V., CIPELLO, R. Microstructure of Polypropylene. Prog. Polym. Sci, v. 26, p. $443-$ 533, 2001.

DIAZ, A. Polipropileno e policarbonato. 1999. 41f. Dissertação (Mestrado)- Escola de engenharia do departamento de engenharia química - DEQUI - UFRS, Porto Alegre, 1999.

FRANCO, P.J. H.; GONZÁLEZ, A.V. Mechanical properties of continuous natural fibrereinforced polymer composites . Composites: Part A. v. 35, p. 339-345. 2003.

GEORGE, J.; BHAGAWAN, S.S.; THOMAS, S. Thermogravimetric and dynamic mechanical thermal analysis of pineapple fibre reinforced polyethylene composites. Journal of thermal analysis, v. 47, p. 1121-1140, 1996.

HOWARD, G. T. Biodegradation of Polyurethane a Review International Biodeterioration \& Biodegradation. v. 49, p. 245-252, 2002.

ICHAZO, M.N.; ALBANO, C.; GONZÁlES, J.; PERERA, R.; CONDAL, M.V. Polypropylene/wood flour composites: treatments and properties. Composite Structures, v. 54, p. 207-214, 2001.

IDICULA, M.; BOUDENNE, A.; UMADAVI, L.; IBOS, L.; CANDAU, Y.; THOMAS, S. Thermophysical properties of natural fibre reinforced polyester composites . Composites Science and Technology. v. 66, p. 2719-2725, 2006.

JOSEPH, V.; MATHEW, G.; JOSEPH, K.; GROENINCKX, G.; THOMAS, S. Dynamic mechanical properties of short sisal fibre reinforced polypropylene composites Composites Part A . v. 34, p. $275-290,2003$.

KAEMPLER, D.; RALFTHOMANN; MÜLHOUPT, R. Melt Compounding of Sydiotactic Polypropylene Nanocomposites containing organophilic Layered Silicates and in Situ Formed Core/ Shell Nanoparticles. Polymer. v. 43, p. 2909-2916, 2002.

LIU, H.; WU, Q.; ZHANG, Q. Preparation and properties of banana fibre-reinforced composites based on high density polyethylene (HDPE)/Nylon-6 blends . Bioresource Technology. v. 100, p. 6088 - 6097, 2009.

MARTINELI, A. L. Desenvolvimento de Compósitos Poliméricos com Fibras Vegetais Naturais da Biodiversidade: uma Contribuição para a Sustentabilidade Amazônica . Polímeros: Ciência e Technologia. v.18, n. 2, p. 92 -99, 2008.

MOURAD, A. I. Thermomechanical Characteristics of Thermally age PE/PP Blends. Materials \& Design. v. 31, p. 918-929, 2010.

MUKHOPADHYAY, S. et al. Effect of ageing of sisal fibres on properties of sisal Polypropylene composite . Polymer Degradation and Stability. v. 93, p. 2048 - 2051, 2008.

PARK, Y.; DOHERTY. W.O.S.; HALLEY, P.J. Development of Lignin Based Resin Coatings and Composites. Industrial Crops and Products, v. 27, p.163 - 167, 2008.

PRACELLA, M. et al. Functionalization, compatibilization and properties of polypropylene composites with Hemp fibres. Composites Science and Technology. v.66, p. 2218 - 2230, 2006.

RAHMAN, R.; HUQUE, M.; ISLAM, N.; NASAN, M. Improvement of physico-mechanical properties of jute fibre reinforced polypropylene composites by post-treatment . Composites. Part A. v. 39, p.1739-1747, 2008. 
RISSON, P.; CARVALHO, G.A.; VIEIRA, S. L.; ZENI, M.; ZATTERA, A. J. Reaproveitamento de Resíduos de Laminados de Fibra de Vidro na Confecção de Placas Reforçadas de Resina Poliéster . Polímeros: Ciência e Tecnologia, v. 3, p. 89-92, 1998.

ROHLMANN, C. O.; HORST, M. F.; QUINZANI, L. M.; D. PAILLA, M. Comparative Analysis of Nanocomposites Based on Polypropylene and Different Montmorillonites. Europen Polymer Journal. v. 44, p. 2749-2760, 2008.

SELKE, A. E. Compósitos Estruturais de Poliéster: Aproveitamento de Lodo Industrial e Fibras de Crisotila e Blenda Náilon 6.6/Quitosana. Dissertação (Mestrado) - Departamento de Quimica, FURB, Blumenau, 2007.

SHIBATA, S.; CAO, Y.; FUKUMOTO, I. Lightweight laminate composites made from kenaf and polypropylene fibres . Polymer Testing. v. 25, p. 142-148, 2005.

SMITH, W. F. Princípios de Ciência e Engenharia dos Materiais. 3. ed. Portugal: McGrawHill, 1996.

VU-KHANH, T., MAJDOUBI, M.E. Entropy Change with Yielding and Fracture of Polypropylene. Theoretical and Applied Fracture Mechanics, v. 51, p. 111-116, 2009.

WANG, S. W.; YONG, W.; BONG, Y. J.; XIE, H.; YONG, M.; PENG, X. F. Crystalline Morphology of $\beta$ nucleated Controlled Reology Polypropylene. Polymer Testing. v. 27, p. 638-644, 2008.

XIAOFEI, M.; CHANG, P. R.; YU, J. Properties of diodegradable thermoplastic pea starch/carboxymethyl cellulose and pea starch/microcrystalline cellulose composites. Carbohydrate Polymers. v. 72, p. 369-375, 2008.

YANG, W.; LIU, Z.; SHAN, G.; MING, Z.; XIE, L. B.; YANG, M. Study on The Melt Flow Behaviour of Glass Bead Filled Polypropylene. Polymer Testing. v. 24, p. 490-497, 2005. 